
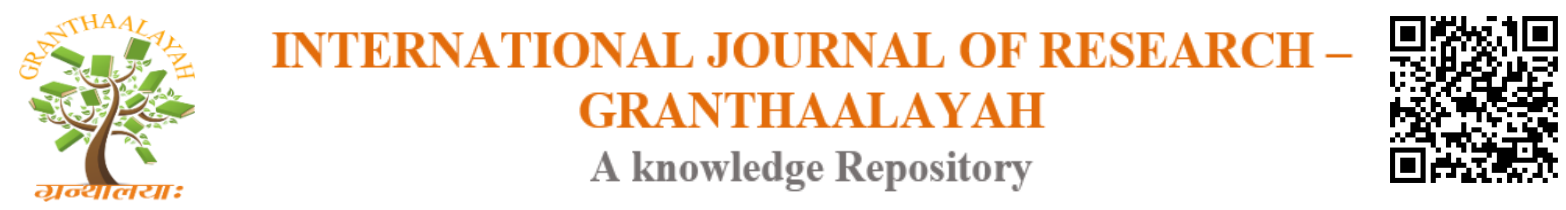

Science

\title{
DETERMINING THE OPTIMAL DIMENSIONS FOR A MECHANISM FROM A WHEELCHAIR USING LABVIEW
}

\author{
Vlad Gheorghita ${ }^{* 1}$, Catalin Gheorghita ${ }^{2}$ \\ ${ }^{*} 1,2$ Department of Manufacturing Engineering, Politehnica University Bucharest, Romania
}

\begin{abstract}
The optimum selection of process parameters plays a very important role to ensure quality of product, to reduce the machining cost and to increase the productivity. Customizing a product to improve performance requires a reliable method to measure performance, in order to evaluate the effects that design changes have on them. A product development process can be thought as a sequence of activities to be completed. This paper has the purpope to analyse the influence of the parameters for equipment from a wheelchair that will overcome obstacles. The fuzzy logic is used through specialized software to optimize several parameters of the proposed mechanism with the purpose to ensure the stability through maintaining horizontality of the equipment. Comparing experimental values with those obtained through the software model, is determined whether the model used is consistent.
\end{abstract}

Keywords: Design Methods; Design Models; Software Engineering; Optimisation; Constraint Modelling.

Cite This Article: Vlad Gheorghita, and Catalin Gheorghita. (2018). "DETERMINING THE OPTIMAL DIMENSIONS FOR A MECHANISM FROM A WHEELCHAIR USING LABVIEW." International Journal of Research - Granthaalayah, 6(1), 240-247. https://doi.org/10.5281/zenodo.1164122.

\section{Introduction}

The development of devices that can improve people's quality of life can be a task for engineering researchers. Over the past several years, researches of motorized equipment were performed by several scientists who have analyzed the types of mechanisms to access obstacles. Sliping, slanting, becoming unstable, sliding, overturning and blocking while climbing steps and stairs are common problems and may cause instability for the user of equipment. There are many studies conducted in areas related to climbing equipment. These include crawler type, leg type, hybrid type and wheeled type. Ghani (Ghani, 2003) investigated an equipment used indoor, evaluating different mechanisms for accesing stairs: track, legs and wheeled combined system, analyzing various forces and couples acting. Quaglia (Quaglia, 2009) analyzed aspects of developing an equipment for climbing stairs, which can move in structured and unstructured environments that can go over obstacles and can go down or up the stairs. The device consists of 
a frame, seat and a linkage mechanism. The framework consists of a chassis built with two motorized units, support for two electric motors, two wheels and a battery. The seat has a tubular structure consisting of a frame and a pivoting wheel. Linkage mechanism is responsible for the relative movement between the frame and the seat during operation. In optimization of a mechanism domain, Cossalter (Viadero-Rueda, 2013) presented a simple numerical approach for optimum synthesis of a class of planar mechanisms, generators of functions, paths and rigid motions. Lio (Viadero-Rueda, 2013) presented a paper which deals with the use of natural coordinates for the synthesis of mechanisms using optimization methods. The modelling of a mechanism with natural coordinates is made using a system of algebraic constraint equations.

In fuzzy logic research, Ali (Ali et al, 1999) presented in their paper an approach in detail to demonstrate the strength of fuzzy logic in modeling a complex system in an efficient manner, with membership functions and fuzzy rule bases. Amaitik (Amaitik et al, 2013) showed fuzzy logic models to select parameters in automated process planning (CAPP) systems.

\section{Mechanism Analysis}

Determination of optimum parameters of any design process is usually a difficult stage where the following aspects are required: knowledge of manufacturing process, empirical equations to develop realistic constraints, specification of equipment capabilities, development of effective optimization criteria, and understanding of numerical optimization techniques. One of the most important features of the design of an equipment for overcoming obstacles is its ability to surmount physical obstructions that may occur (e.g. threshold, stairs). The basic requirements for a product of this type are: to enable to move along various kinds of surfaces (e.g. uneven surface, sand, snow); to have a small size; to enable the movement up and down the stairs. A shape of the proposed mechanism is presented in Figure 1. The mechanism consists of: a drive wheel $R_{1}$, two power driven wheels $R_{2}$ and $R_{3}$ articulated through two arms. Parallelogram mechanism is placed in the center and is operated by Link 2 through a lever. System stability is achieved by wheel $R_{3}$ and Link 1.

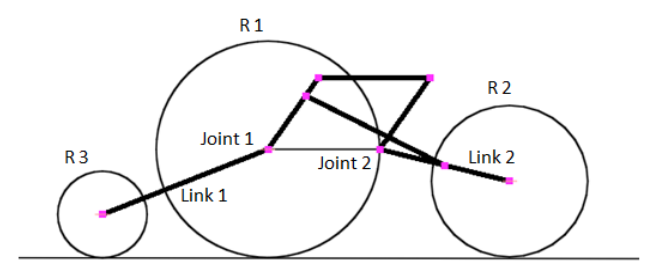

Figure 1: Diagram of the mechanism

The kinematic model of the mechanism shown in Figure 2, is built and it is simulated in Matlab software.

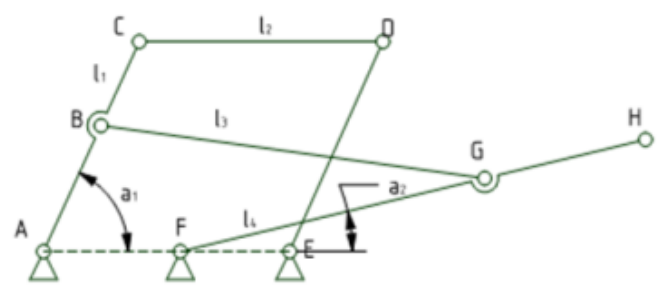

Figure 2: Analysis of the mechanism 
A kinematic analysis of a connection, is used to assess its performance keeping the design goal and to ensure that the mechanism has no flaws. A complicated structure will determine unnecessary energy losses. Models and references to prior experimental work have identified important design parameters of similar devices, for ensuring the horizontal and vertical seat position. The seat connects with the mechanism in points $C$ and $D$, and the wheel driven $R_{2}$ in $H$ point. Changing the position of lever FG is transmitted to the mechanism ACDE through the arm BG. The angle $\alpha_{2}$ is the angle made by FH link with the horizontal.

The design of experiments has an important effect on the number of experiments needed, being essential to have a proper design. An approach to model an equipment requires performance data related to the design parameters. The domain interval of input and output variables is presented in table 1 . In this study, four dimensions of the link $\left(l_{1}, l_{2}, l_{3}, l_{4}\right)$ have been considered with their range as design parameters and were improved using the optimization procedure.

Table 1: Domain intervals of input and output variables

\begin{tabular}{|l|l|l|}
\hline Variable & Range & Unit \\
\hline \multicolumn{3}{|l|}{ Input variables } \\
\hline$l_{1}$ & $0-150$ & {$[\mathrm{~mm}]$} \\
\hline$l_{2}$ & $0-300$ & {$[\mathrm{~mm}]$} \\
\hline$l_{3}$ & $0-350$ & {$[\mathrm{~mm}]$} \\
\hline$l_{4}$ & $0-250$ & {$[\mathrm{~mm}]$} \\
\hline \multicolumn{4}{|l|}{ Output variables } \\
\hline$\alpha_{2}$ & $0-90$ & {$\left[{ }^{\circ}\right]$} \\
\hline
\end{tabular}

A data collection considers how the experimental factors, controlled and uncontrolled, fit together into a model that will meet the specific objectives of an experiment and satisfy the practical constraints of resource and time. Determining what levels of a variable to test requires an in-depth understanding of the process, including the minimum, maximum, and current value of the parameter. In a experimental design, all possible combinations of the values of factors must be tried. The experiment combinations are chosen to provide sufficient information to determine the effects of each factor. The experimental data collected are presented in table 2 .

Table 2: Experimental data

\begin{tabular}{|l|l|l|l|l|}
\hline Exp. No. & $\mathbf{l}_{\mathbf{1}}[\mathbf{m m}]$ & $\mathbf{l}_{\mathbf{1}}[\mathbf{m m}]$ & $\mathbf{l}_{\mathbf{3}}[\mathbf{m m}]$ & $\mathbf{l}_{\mathbf{4}}[\mathbf{m m}]$ \\
\hline 1. & 50 & 100 & 116.6 & 83.3 \\
\hline 2. & 50 & 200 & 233.2 & 166.6 \\
\hline 3. & 50 & 300 & 350 & 233.2 \\
\hline 4. & 100 & 100 & 233.2 & 233.2 \\
\hline 5. & 100 & 200 & 350 & 83.3 \\
\hline 6. & 100 & 300 & 116.6 & 166.6 \\
\hline 7. & 150 & 100 & 350 & 166.6 \\
\hline 8. & 150 & 200 & 116.6 & 233.2 \\
\hline 9. & 150 & 300 & 233.2 & 83.3 \\
\hline
\end{tabular}

The effect of many different parameters on the performance characteristic in a condensed set of experiments can be examined by using the orthogonal array experimental design proposed by 
Taguchi. The range of the angle $\alpha_{2}$ was $\pm 30^{\circ}$, this variation being determined by the height of the obstacles taken into consideration.

\section{Fuzzy Logic LabView}

LabView is a programming environment that creates programs using a graphical notation, by connecting functional nodes with wires through which data flows. Thus, for analyzing the effect of kinematics parameters on the process, a LabView application based on the Control and Stimulation module, Fuzzy System Designer, was developed. Fuzzy logic is a method of rulebased decision making used by expert systems and process control. In our case, the mechanism of inference used is Mamdani and the distribution chosen for the membership function for the inputs and outputs is triangular with 3 states.

In LabView, Fuzzy System Designer and Fuzzy Logic VIs were used to design and control fuzzy systems. This fuzzy system consists of three main parts: linguistic variables, membership functions, and rules. Linguistic variables usually have an odd number of linguistic terms, with a middle linguistic term and symmetric linguistic terms at each extreme. A fuzzy controller requires at least one input linguistic variable and one output linguistic variable. The range of each parameter was set at three different levels, namely low, medium and high. Membership functions shown in figure 4 are numerical functions corresponding to linguistic terms. A membership function represents the degree of membership of linguistic variables within their linguistic terms. The degree of membership is continuous between 0 and 1 , where 0 is equal to $0 \%$ membership and 1 is equal to $100 \%$ membership. In addition, it is possible to use any shape of membership sets: triangular, trapezoidal and gaussian. Also, LabVIEW application helps in verifying each block of the system through boolean, numeric and graph indicators.
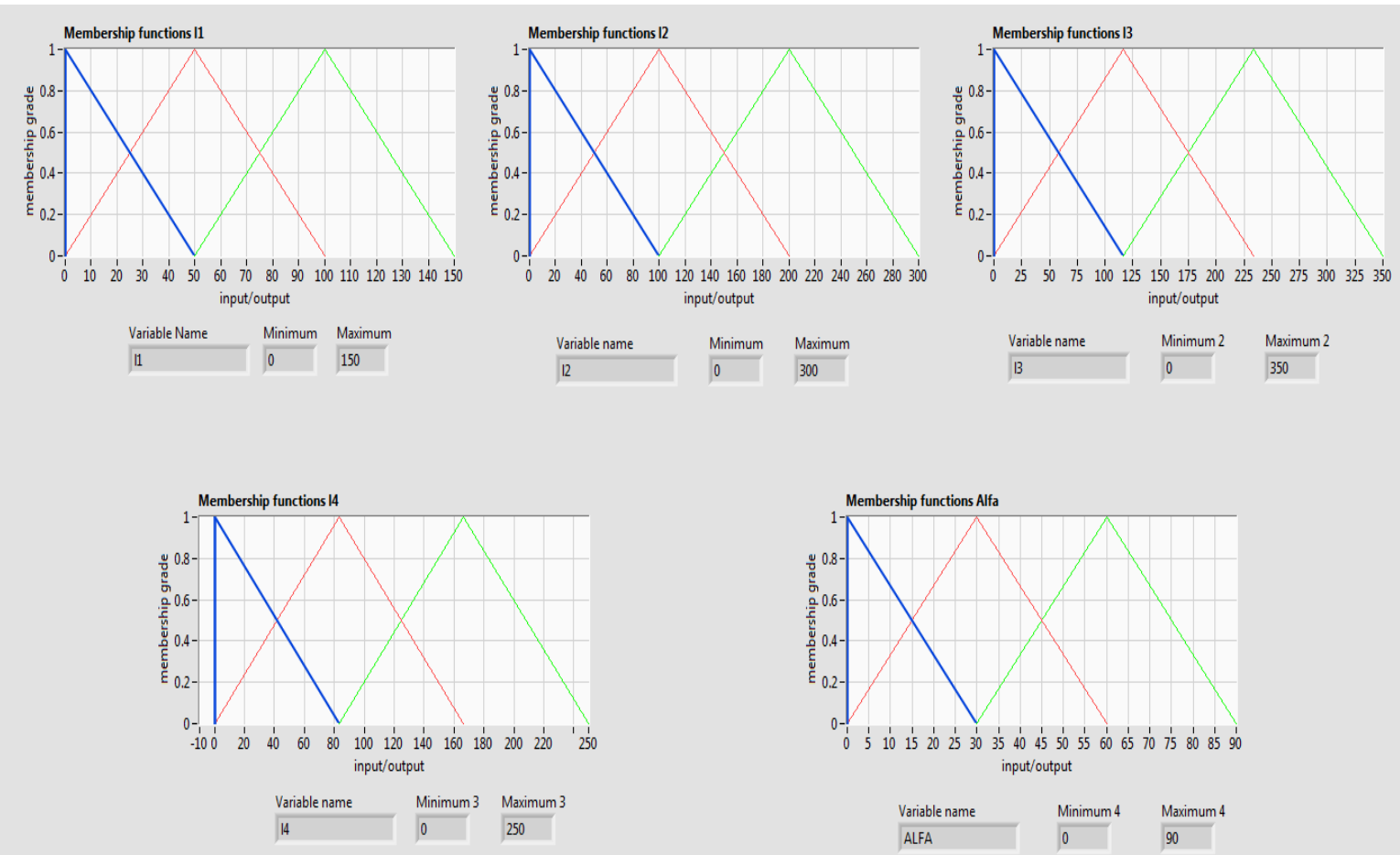

Figure 4: Membership function 
Most traditional control algorithms require a mathematical model of the system to be controlled. However, many physical systems are difficult or impossible to model mathematically. Many processes are either nonlinear or too complex for you to control with traditional strategies. After a fuzzy controller fuzzifies the input values of a fuzzy system, the fuzzy controller uses the corresponding input linguistic terms and the rule base to determine the resulting linguistic terms of the output linguistic variables. The fuzzy logic controller uses an antecedent connective to determine how to calculate the truth value of the aggregated rule antecedent (LabView PID and Fuzzy Logic Toolkit User Manual, 2009). There were created complete rule bases with at least one active rule for each possible combination of input linguistic variables and linguistic terms. The "and" connective specifies how the fuzzy logic controller relates the antecedents to determine the truth value for the aggregated rule antecedent.

For four input linguistic variables with three linguistic terms each, the total number of possible rules is $\mathrm{N}=3^{4}=81$. In this case, all rules have the weight equal to 1 . The number of fuzzy rules in a fuzzy system is related to the number of sets for each input variable. There are four input variables which are classified into nine fuzzy sets and therefore are nine states to be determined. The "and" and "or" used in the rules will apply to the fuzzy "and" and "or" operations, respectively. The rules are described in the figure below:

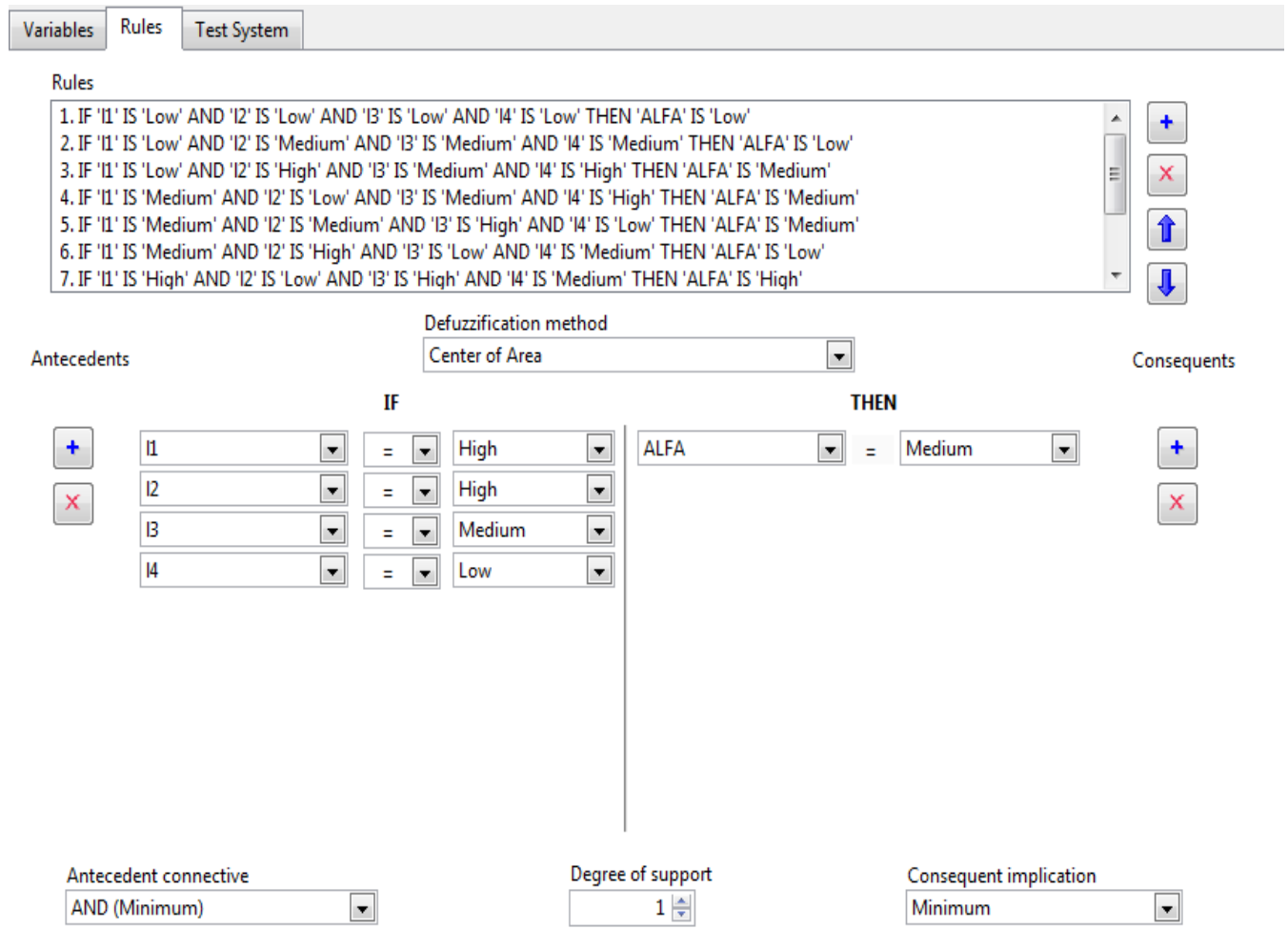

Figure 5: Defining fuzzy rules in LabView

The designed fuzzy controller used mathematical methods to perform defuzzification. Once the rules are evaluated, the variables lenghts are defuzzified and converted into the corresponding output variable. The block diagram that contained the graphical source code of a the LabView program which separate it from the user interface in a logical manner is presented in the following figure. 


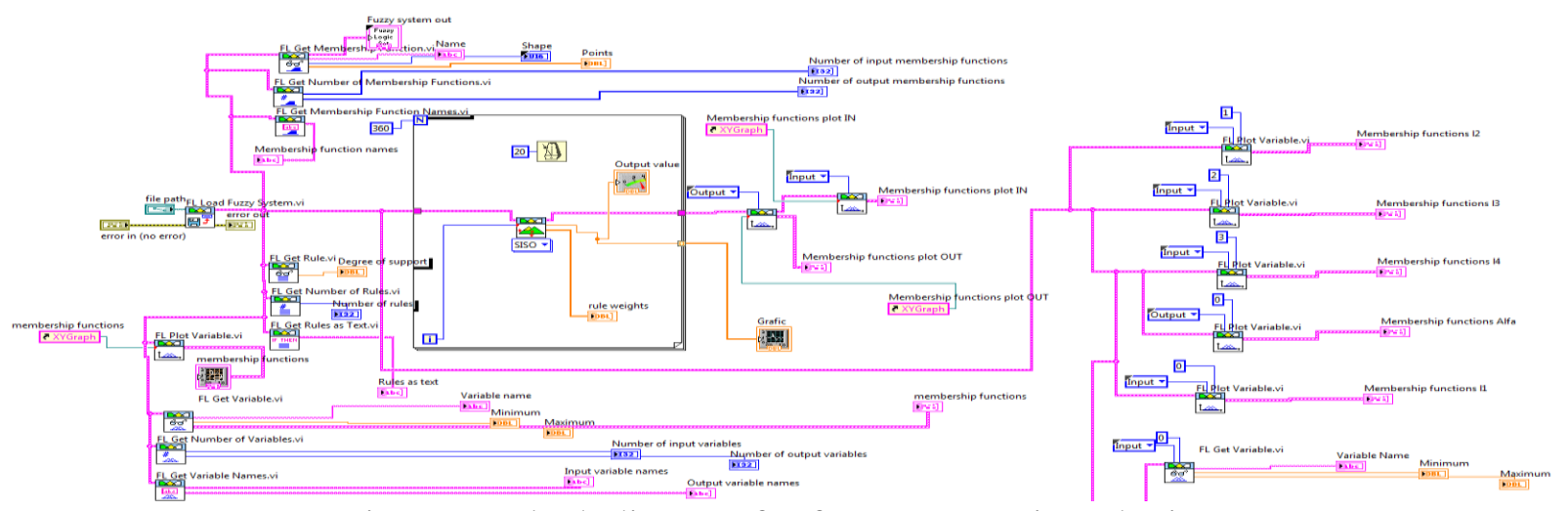

Figure 6: Block diagram for fuzzy system in LabView

\section{Results and Discussions}

The tasks to be completed for each activity in engineering design are complicated and require assurance of complex criteria, such as material failure due to stresses, vibrations, thermal characteristics. Such complex analysis may be very resource intensive, yet the success and quality of a product cannot be assured without this analysis of mechanical effects. If performance issues were not resolved with suitable modeling and analysis, many failures would be experienced without any guarantee of future performance. Thus, in the Lab view application the response surface design methodology is used to refine models after the important factors were determined using factorial designs. These methods are exclusively used to examine the surface or the relationship between the response and the factors affecting the response. Once the important factors have been identified, the next step is to determine the settings for these factors that result in the optimum value of the response. The influence of independent variables on output values is shown in figure 7.

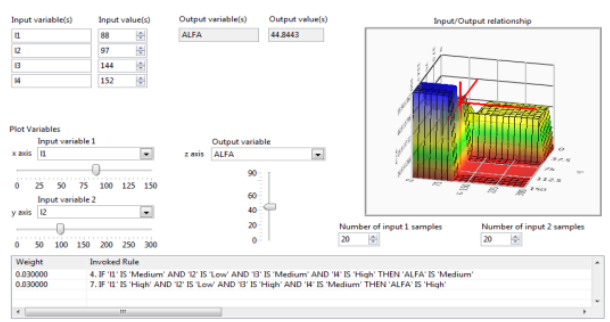

a) Inputs: $1_{1}, l_{2}$

Output: $\alpha_{2}$

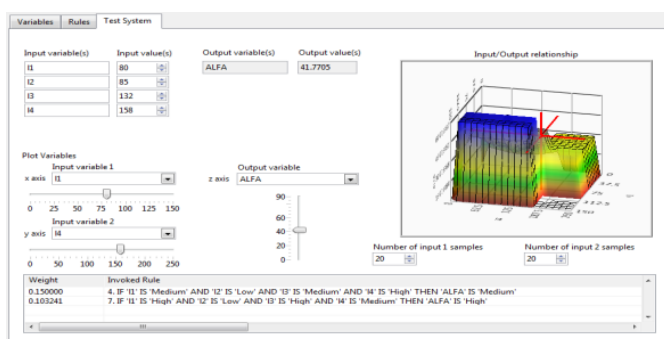

c) Inputs: $1_{1}, 1_{4}$

Output: $\alpha_{2}$

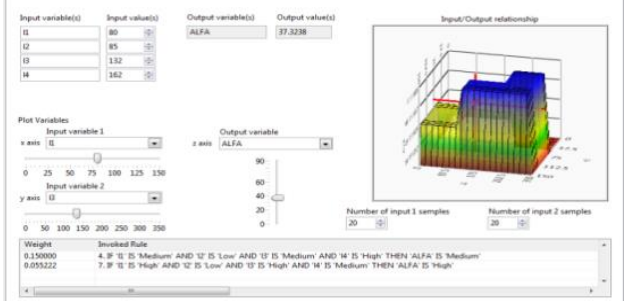

b) Inputs: $1_{1}, l_{3}$

Output: $\alpha_{2}$

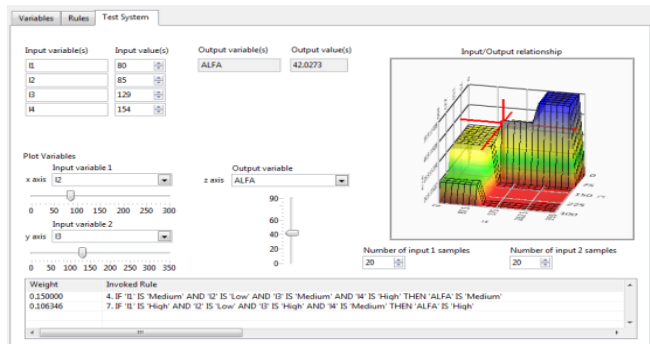

d) Inputs: $1_{2}, 1_{3}$

Output: $\alpha_{2}$

Figure 7: The influence of surface of parameters 
The largest values of the inclination angle of the actuating arm is obtained for the variation of the length $l_{1}$ in the interval $(80,90) \mathrm{mm}$ and the length $l_{3}$ in the interval $(140,150) \mathrm{mm}$. The angle analyzed increases at combination of $l_{2}$ and $l_{4}$ with $8,13 \%$ compared to the combination $l_{1}$ and $l_{3}$. The process must ensure consideration of each of the elements necessary for successful design, ensure that all consequences of the application of the designed product throughout its lifetime are examined and resolve conflicts between the functional requirements and external constraints. The mechanism was designed, and with the help of a dial comparator, the variations of the angle that ensure the horizontal position of the platform support of the equipment when negotiating the obstacles encountered on the route was measured. Experimental data were compared to those obtained with the model created with Fuzzy Logic Labview.

Table 5: Error between measured and predicted values

\begin{tabular}{|l|l|l|l|}
\hline Exp. No. & Experimental values $\alpha_{2}\left[^{\circ}\right]$ & Labview Fuzzy Model $\left[{ }^{\circ}\right]$ & Error [\%] \\
\hline 1. & 29.79 & 30.41 & 3.22 \\
\hline 2. & 29.98 & 30.23 & 3.28 \\
\hline 3. & 30.01 & 30.16 & 3.29 \\
\hline 4. & 29.02 & 29.59 & 3.31 \\
\hline 5. & 29.24 & 29.86 & 3.27 \\
\hline 6. & 29.31 & 29.02 & 3.47 \\
\hline 7. & 30.04 & 30.17 & 3.29 \\
\hline 8. & 29.46 & 29.99 & 3.27 \\
\hline 9. & 29.98 & 30.05 & 3.32 \\
\hline
\end{tabular}

It can be observed that the obtained results have little variation. Confirmation tests of randomly selected conditions were also undertaken to further demonstrate the effectiveness of the proposed model. The suitable model for the range of parameters values was the first order prediction model. This model is simple and was used for the optimization of the process. Thus, the best value is obtained at combination represented by $l_{1}=50 \mathrm{~mm}, l_{2}=100 \mathrm{~mm}, l_{3}=116.6 \mathrm{~mm}$ and $l_{4}=$ $83.3 \mathrm{~mm}$. To determine the model, the length parameters $\left(1_{1}, 1_{2}, 1_{3}, 1_{4}\right)$ were considered independent variables and the alfa angle was a dependent variable.

\section{Conclusion}

The optimum selection of process parameters plays a significant role to ensure quality of product, to reduce the machining cost and to increase the productivity of any process. The work had presented an experimentation approach to studying the influence of length parameters of the elements of a mechanism for overcoming obstacles, by measuring the variation of the angle that ensure the horizontality of the product. The angle equation show that the lengths have a major role in maintaining the stability of the equipment, thus it grows by increasing the dimensions lenghts. Effectiveness of fuzzy logic models has been determined by comparing experimental results. Simple models were developed and are to be validated with future experimental results. It has been concluded that fuzzy rule based modelling can be used to predict the accuracy of the design process successfully. 


\section{References}

[1] Amaitik, S. (2013). "FUZZY LOGIC MODELS FOR SELECTION OF MACHINING PARAMETERS IN CAPP SYSTEMS." International Journal of Computer and Information Technology Volume 02 - Issue 02, 279-285, ISSN: 2279-0764.

[2] Ali Y.M., Zhang L.C. (1999). "SURFACE ROUGHNESS PREDICTION OF GROUND COMPONENTS USING A FUZZY LOGIC APPROACH." Journal of Materials Processing Technology, Volume 89-90, 561-568.

[3] Basim A. (2013). "MODIFICATION APPROACH OF FUZZY LOGIC MODEL FOR PREDICTING OF CUTTING FORCE WHEN MACHINING NICKEL BASED HASTELLOY C-276." American Journal of Engineering and Applied Sciences 3, 207-213, ISSN 1941-7020.

[4] Ghani A. (2003). "CONTROL OF A MULTI FUNCTION WHEELCHAIR FOR DISABLED/ELDERLY MOBILITY." University of Sheffield.

[5] Johnson G., Jennings R. (2006). "LABVIEW GRAPHICAL PROGRAMMING FOURTH EDITION." Mcgraw-Hill, ISBN: 978-0-07-150153-8.

[6] "LABVIEW PID AND FUZZY LOGIC TOOLKIT USER MANUAL" (2009). National Instruments.

[7] Lawn J.M, Sakai T., Kuroiwa M. And Ishimatsu T. (2001). "DEVELOPMENT AND PRACTICAL APPLICATION OF A STAIR CLIMBING WHEELCHAIR IN NAGASAKI." International Journal of HWRS-ERC.

[8] Morales R., Feliu V., Gonzalez A. (2010). "OPTIMIZED OBSTACLE AVOIDANCE TRAJECTORY GENERATION FOR A RECONFIGURABLE STAIRCASE CLIMBING WHEELCHAIR." Robotics and Autonomous Systems, volume 58 Issue 1, 97-114, doi:10.1016/j.robot.2009.07.020.

[9] Otto K., Wood K. (2001). "PRODUCT DESIGN: TECHNIQUES IN REVERSE ENGINEERING AND NEW PRODUCT DEVELOPMENT.” Prentice Hall, ISBN 0-13-0212717.

[10] Quaglia G, Franco W., Oderio R. (2009). "WHEELCHAIR.Q, A MECHANICAL CONCEPT FOR A STAIR CLIMBING WHEELCHAIR." Proceeding of IEEE International Conference on Robotics and Biomimetics, Guilin, China, doi: 10.1109/robio.2009.5420572.

[11] Travis J., Kring J. (2006). "LABVIEW FOR EVERYONE: GRAPHICAL PROGRAMMING MADE EASY AND FUN THIRD EDITION.” ISBN-10: 0-13-185672-3.

[12] Viadero-Rueda F., Ceccarelli M. (2013). "NEW TRENDS IN MECHANISM AND MACHINE SCIENCE: THEORY AND APPLICATIONS IN ENGINEERING.” Springer, New York, doi: 10.1007/978-94-007-4902-3.

[13] Yoneda K., Ota Y. (2001). "DEVELOPMENT OF A HI-GRIP STAIR CLIMBING CRAWLER WITH HYSTERESIS COMPLIANT BLOCKS." Proceeding of 4th International Conference on Climbing and Walking Robots CLAWAR, 569-576

[14] Yun T., Ting W., Chen Y., Xiaofan L. (2010). "THE RESEARCH OF TENSION OPTIMAL ESTIMATION AND STAIR-CLIMBING ABILITY OF TRANSFORMATION WHEELCHAIR ROBOT." Proceeding of 29th Chinese Control Conference, Beijing, China

\footnotetext{
*Corresponding author.

E-mail address: vlad.gheorghita@ upb.ro
} 